\title{
A randomized controlled trial on the effect of incomplete milking during the first 5 days in milk on culling hazard and on milk production and composition of dairy cows
}

\author{
C. Krug, ${ }^{*}$ P.-A. Morin, † P. Lacasse,‡ D. E. Santschi,§ J.-P. Roy,† J. Dubuc, $†$ and S. Dufour*1 \\ *Département de pathologie et microbiologie, and \\ †Département de sciences cliniques, Faculté de médecine vétérinaire, Université de Montréal, 3200 Rue Sicotte, St-Hyacinthe, Québec, \\ J2S 2M2, Canada \\ ¥Centre de recherche et de développement de Sherbrooke, Agriculture Canada, 2000 College, Sherbrooke, Québec, J1M 0C8, Canada \\ $\S$ Valacta, 555 Boulevard des Anciens Combattants, Sainte-Anne-de-Bellevue, H9X 3R4, Canada
}

\section{ABSTRACT}

An incomplete milking in early lactation could help limit negative energy balance in dairy cattle, but its potential effects on culling hazard and on milk production and composition throughout the entire lactation are unknown. The objective of this study was to evaluate the effect of an incomplete milking during the first $5 \mathrm{~d}$ in milk on culling hazard, milk weight, milk fat and protein concentrations, and energy-corrected milk (ECM) yield during the whole lactation. A randomized controlled trial was conducted in 13 dairy farms near St-Hyacinthe, Quebec, Canada. Approximately 1 mo before expected calving, Holstein multiparous cows calving between December 2013 and March 2015 (n = 846 cow lactations) were randomly assigned to a control or a treatment group. Cows in the control group were milked conventionally, whereas cows in the treatment group were submitted to an incomplete milking protocol (maximum of 10, 12, and $14 \mathrm{~L} / \mathrm{d}$ of milk was collected on days in milk $1-3,4$, and 5 , respectively). All farms were registered on Dairy Herd Improvement Association, which was used to obtain records on culling, monthly milk yield, and milk fat and protein concentrations. In addition, daily milk yield records were available for 6 farms. A Cox proportional hazards model with a herd frailty term was fitted to the data to compare culling hazard among treatment groups. Regarding milk production and composition, 4 linear mixed models with herd as a fixed effect, cow as a random effect, and using an autoregressive covariance structure were used to study the effect of the incomplete milking on (1) milk weight, (2) milk fat concentration, (3) milk protein concentration, and (4) ECM yield.

Received October 18, 2017.

Accepted January 16, 2018

${ }^{1}$ Corresponding author: simon.dufour@umontreal.ca
Culling hazard did not differ among treatment groups (hazard ratio $=1.0 ; 95 \% \mathrm{CI}=0.82,1.3$ ). We observed no differences in milk weight, milk fat, or protein concentration among treatment groups between weeks in milk (WIM) 2 and 44 (the studied period). We noted a difference in ECM between treatment groups for WIM 38 , with incompletely milked cows producing less milk than conventionally milked cows $(-2.7 \mathrm{~kg} / \mathrm{d} ; 95 \%$ CI $=-0.02,-5.2 \mathrm{~kg} / \mathrm{d}$ ), but no differences were found for any of the other WIM. These results suggest that this strategy for controlling the negative energy balance has negligible effect on cow productivity.

Key words: dairy cattle, incomplete milking, culling, milk production

\section{INTRODUCTION}

In dairy cows, the transition period is marked by substantial nutritional, metabolic, hormonal, and immunological changes (van Knegsel et al., 2007; Ster et al., 2012). During this period, cows are in a state of negative energy balance (NEB) that occurs because the demand for nutrients for milk production increases rapidly and exceeds the supply of nutrients provided by food intake (Grummer et al., 2004). This NEB results in lower blood glucose levels and the mobilization of body reserves to provide additional energy, leading to elevated blood concentration of metabolites, such as fatty acids and BHB (Busato et al., 2002). High concentrations of these metabolites have been associated with a state of immunosuppression (van Knegsel et al., 2007; Ster et al., 2012), increased risk of infectious diseases (Suriyasathaporn et al., 2000), metabolic diseases, reduced milk production (Duffield et al., 2009), and higher culling risk (Roberts et al., 2012).

Decreasing the imbalance between nutrient requirements and energy intake (i.e., the NEB) should reduce the incidence of metabolic and infectious diseases in 
dairy cows. The classic approach to decrease that imbalance is to increase energy density of the diet offered during this period (Grummer et al., 2004). Another option is to temporarily decrease energy demands, by slowing down the increase in milk production for a few days just after calving. Once a day milking during the first week in milk (WIM) seems to have this effect, by temporarily reducing the energetic requirements and, therefore, the NEB (Loiselle et al., 2009; O'Driscoll et al., 2012). However, it also has a negative carryover effect on milk production for the rest of the lactation, possibly due to the lower stimulation of prolactin hormone (Lacasse et al., 2011).

Carbonneau et al. (2012) have shown that reducing milk output by milking cows incompletely (collecting about one third of expected milk production), twice daily until d 5 after calving while maintaining the stimulus of frequent milk removal, improves metabolic status and immune functions without having a carryover effect on subsequent milk production. Although the results of their study are very promising, it was conducted on a limited number of animals (16 treated and 15 control cows) in experimental research station conditions. These results cannot, consequently, be generalized to commercial farms. Therefore, a randomized controlled trial (RCT) was conducted on 13 commercial dairy farms to evaluate the effect of an incomplete milking protocol (Morin et al., 2018). The RCT showed a marked decrease in BHB blood concentration and in odds of hyperketonemia among cows milked incompletely. The aim of the present research was to investigate the effect of the incomplete milking protocol on culling hazard and on milk production and composition using the large data set generated by the Morin et al. (2018) study.

\section{MATERIALS AND METHODS}

\section{Sample Size Calculations}

The original study was designed to investigate the effect of an incomplete milking protocol on ketonemia, odds of hyperketonemia, reproductive performances, odds of infectious diseases (e.g., mastitis, metritis), culling hazard and, finally, milk production and composition (Krug et al., 2017; Morin et al., 2018). Among all the outcomes studied, the outcome requiring the largest sample size was odds of hyperketonemia, which required the recruitment of 400 cows per treatment group (Morin et al., 2018). The sample size for the RCT described in our study was, therefore, determined for answering this latter research objective. Nevertheless, power calculations using the POWER procedure in SAS 9.4 (SAS Institute Inc., Cary, NC) were con- ducted to estimate the differences in milk weight, fat and protein concentrations, and ECM that could be detected using the available data. Using an $\alpha$ of 0.05 , and assuming a standard deviation of $5.0 \mathrm{~kg} / \mathrm{d}$ for milk weight and ECM and of 0.5 percentage points for milk fat and protein concentrations, we estimated that differences in milk weight and ECM $\geq 1.2 \mathrm{~kg} / \mathrm{d}$ and of fat and protein concentration $\geq 0.12$ percentage points could be detected with $>90 \%$ power with the available data. Clustering of observations by cow and herd was not considered for these calculations; therefore, the minimal detectable differences presented are likely to be slightly optimistic.

\section{Herds and Cows}

Our study was an RCT conducted on multiparous cows from a convenient sample of 13 commercial dairy farms. The complete research protocol is described by Morin et al. (2018). Briefly, to be selected, farms had to be in the vicinity of Saint-Hyacinthe (Quebec, Canada); to accept to follow the standardized research protocol; to participate in a DHIA program; to have computerized health records; to use a milking system allowing measurement of the harvested milk in real time during milking; and to share their herd health, DHIA, and daily milk weight (if available) data with the research group. The study protocol was accepted by the Animal Ethics Committee of the Université de Montréal (rech-1701).

In each herd, all multiparous cows calving between December 2013 and March 2015 were randomly allocated at the time of dry off to a treatment or a control group using a random number generator. Cows in the treatment group were milked incompletely during the first 5 DIM, with a maximum of 10, 10, 10, 12, and 14 L/d collected on DIM 1, 2, 3, 4, and 5, respectively. This protocol was derived from the one investigated by Carbonneau et al. $(2012 ; 6,8,10,12$, and $14 \mathrm{~L} / \mathrm{d}$ on DIM $1,2,3,4$, and 5 , respectively) in an attempt to make the protocol more practical for milk producers. More specifically, farms with 2 milkings/d were informed to collect $5,5,5,6$, and $7 \mathrm{~L} /$ milking on DIM 1, 2, 3, 4, and 5 , respectively. Farms with 3 milkings/d were informed to divide the maximum amount allowed per day in 3 . In the herd using an automatic milking system (AMS), cows from the treated and control groups were milked twice a day in the maternity pen during the first 5 DIM and then sent to the AMS for the remaining of the lactation. In all other herds, cows in the control group were milked conventionally according to the farm practices. The majority of farms $(12 / 13)$ had automatic teat cup removers, with detachment at a mean milk flow rate of $600 \mathrm{~g} / \mathrm{min}$ (range $=300$ to $1,200 \mathrm{~g} / \mathrm{min}$ ). In 6 farms, 
producers reported not milking cows completely during the first 2 DIM as part of their conventional milking routine. Because group allocation influenced how cows were milked, dairy producers could not be blinded to treatment group.

\section{Milk Production and Composition Data}

In 6 of the 13 participating farms, daily milk production was recorded automatically by the herd parlor or automatic milking system software and these data were retrieved directly from the producers' computerized records. In the remaining herds, the participating producers were asked to record milk production manually, at least once a week, for the first 4 WIM. In these herds, subsequent monthly milk production data were retrieved from DHIA records. Additionally, DHIA records were used to obtain monthly milk components (milk fat and protein concentration, in \%), culling date, and lactation duration for cows not culled during the lactation.

For each cow and for each day with a milk yield record, ECM was calculated using the following formula (NRC, 2001):

$$
\begin{gathered}
\operatorname{ECM}(\mathrm{kg} / \mathrm{d})=12.55 \times \text { fat }(\mathrm{kg} / \mathrm{d})+7.39 \\
\times \operatorname{protein}(\mathrm{kg} / \mathrm{d})+0.2595 \times \text { milk yield }(\mathrm{kg} / \mathrm{d}) .[1]
\end{gathered}
$$

To calculate fat yield $(\mathrm{kg} / \mathrm{d})$, fat concentration (\%) was multiplied by milk yield $(\mathrm{kg} / \mathrm{d})$ of the same test date. Protein yield $(\mathrm{kg} / \mathrm{d})$ was calculated in the same way. For farms with daily milk records, means for fat and protein yields from the cow's previous and following DHIA tests were used to compute ECM whenever a milk yield record was available on a given day, but without fat and protein yield data (i.e., between DHIA tests). Due to higher oscillations in fat and protein yields at the beginning of the lactation, this approximation was only used after 30 DIM. Before 30 DIM, only milk yield, fat, and protein data from the actual DHIA test day (for which both milk production and composition data were available) were used for estimating ECM in farms with daily milk records. Therefore, before 30 DIM, approximately 1 ECM observation was available per cow (the DHIA record) for all herds. After 30 DIM, herds with daily milk yield had daily ECM observations until the date of the last DHIA test, whereas herds with monthly milk yield had generally one observation per month.

\section{Data Management and Statistical Analyses}

Culling Hazard. First we assessed whether treatment group affected culling hazard. This first step was important, as the association between treatment and milk production could be biased if a higher proportion of cows were excluded (i.e., culled) earlier in their lactation in one group rather than in the other. Time to culling was defined as the number of days from calving until the cow was culled (left the farm or died). Cows were followed until the end of their lactation or until a maximum of 450 DIM (right-censoring) or culling (whichever comes first). A Cox model with a herd frailty term, to account for the data structure, was fitted to the data using the PHREG procedure in SAS. The general model was

$$
\mathrm{h}_{\mathrm{i}}(\mathrm{t})=\lambda_{0}(\mathrm{t}) \exp \left(\beta_{1} \mathrm{Tx}_{\mathrm{i} 1}\right)+\varepsilon_{\mathrm{i}},
$$

where $h_{i}(t)$ is the culling hazard for the ith cow at time $t ; \lambda_{0}(t)$ is the baseline hazard function; $\beta_{1}$ is the coefficient for the treatment group $\left(\mathrm{Tx}_{\mathrm{i} 1}\right.$; conventional vs. incomplete milking); and $\varepsilon_{\mathrm{i}}$ represents the unobserved heterogeneity, accounting for difference between herds. Using this model, the culling hazard ratio (HR) between conventionally and incompletely milked cows can be computed simply by exponentiating $\beta_{1}$ using the natural base logarithmic transformation.

Parity group (categorized as parity 2 and $\geq 3$ ) was tested as a potential effect modifier of the treatmentculling hazard relationship by adding the main term and 2-way interaction term with treatment group in the model. To evaluate if the treatment effect varied as function of time (i.e., the proportional hazards assumption), the significance of a 2-way interaction term between a time variable and the treatment group variable were added to the model. More specifically, we investigated whether the effect of treatment on culling hazard would increase or decrease exponentially (using DIM natural logarithm as time variable), or if it would change at a given time point (testing several dichotomous time variables with cutoffs at 21,28 , and 35 DIM). In all cases, 2-way interaction terms (effect modifiers or time variables) were retained if $P<0.05$. The assumption of independent censoring was checked as described by (Dohoo et al., 2009). Kaplan-Meier survival curves for each treatment group were produced using STATA/MP 12.0 (StataCorp, College Station, TX).

Milk Production and Composition. Four linear mixed models were used to quantify the effect of treatment group on (1) milk weight $(\mathrm{kg} / \mathrm{d}),(2)$ milk fat (\%), (3) milk protein (\%), and (4) ECM ( $\mathrm{kg} / \mathrm{d})$. The SAS MIXED procedure was used to estimate all 4 models. Herd was included in the models as a fixed effect to account for correlation between cows within each farm. A random cow intercept with an autoregressive covariance structure was used to account for dependency 
between milk measurements from the same cow, and for the higher correlation between measurements collected closer in time (i.e., a repeated measures model). Treatment group and an interaction term between treatment group and WIM were forced into all models to investigate the effect of the treatment for each WIM. The Tukey adjustment was used to adjust for multiple comparisons. The general model was

$$
\begin{gathered}
\mathrm{Y}_{\mathrm{ij}}=\beta_{0}+\beta_{1} \mathrm{Tx}_{\mathrm{j}}+\beta_{2} \mathrm{WIM}_{\mathrm{ij}}+\beta_{3} \mathrm{Tx}_{\mathrm{j}} \times \mathrm{WIM}_{\mathrm{ij}} \\
+\beta_{4} \text { Herd }+\mathrm{u}_{0 \mathrm{j}}+\mathrm{e}_{0 \mathrm{ij}},
\end{gathered}
$$

where $Y_{\mathrm{ij}}$ is the predicted milk weight (model 1), milk fat (model 2), milk protein (model 3) concentrations, or ECM (model 4) for the ith day from the jth cow; $\beta_{0}$ is the intercept; $\beta_{1}$ is the regression coefficient for the treatment group $\left(\mathrm{Tx}_{\mathrm{j}}\right.$; conventional vs. incomplete milking); $\beta_{2}$ is the WIM effect; $\beta_{3}$ is the treatment $\times$ WIM interaction; $\beta_{4}$ is the herd fixed effect included to account for clustering of cows by herd; and $\mathrm{u}_{0 \mathrm{j}}$ and $\mathrm{e}_{0 \mathrm{ij}}$ are the cow random intercept and measurement error term, respectively (assumed to follow approximately normal distributions). Using this model, least squares means can be estimated per treatment group for each WIM using the $\beta_{1}, \beta_{2}$, and $\beta_{3}$ terms.

Parity group was tested as a potential effect modifier of the treatment-milk yield or treatment-composition relationships by adding the main term and 2- and 3-way interaction terms with treatment group and WIM in the models. Parity was retained as an effect modifier if the 3 -way interaction term yielded $P<0.05$ on the $F$ test. Residuals were visually examined for each model to evaluate normality using quantile-quantile plot and histogram of residuals. Assumption of homoscedasticity was assessed visually using plot of the residuals against predicted values.

\section{RESULTS}

\section{Description of Study Population}

Participating herds had a mean (SD) number of 103 (51) milking cows and a mean (SD) 305-d milk yield of $9,973(660) \mathrm{kg} / \mathrm{cow}$. Herds were mainly housed in freestalls $(9 / 13$ herds). In the majority of herds, cows were milked twice a day (11/13 herds), in 1 herd cows were milked 3 times a day, and 1 herd used an AMS. Most farms fed TMR (11/13 herds) and used monensin supplementation (11/13 herds). Conventionally milked cows produced a mean (SD) of 6.0 (3.3), 20.9 (9.9), 25.9 (8.9), 28.8 (7.9), and 30.1 (9.1) L of milk on DIM 1, 2 , 3,4 , and 5 , respectively.
In total, 846 cow lactations were enrolled in the project (838 animals, in which 8 animals were enrolled for 2 different lactations), but 25 cow lactations were not included in the study because farmers inadvertently changed their treatment group $(14 / 25)$ or because cows entered the study before formal randomization $(11 / 25)$. From the 14 cows that were inadvertently changed from one treatment group to another, 7 were from the conventional milking group and 7 were from the incomplete milking group.

\section{Culling}

Two herds stopped DHIA recording during the RCT. Consequently, time to culling or lactation duration could not be computed for 33 cow lactations (15 incompletely and 18 conventionally milked). In addition, 40 cow lactations (21 incompletely and 19 conventionally milked) enrolled in the project could not be matched to their DHIA record. Finally, for 16 cow lactations (9 incompletely and 7 conventionally milked) ending up with censuring (i.e., no culling), exact lactation duration was missing. In the end, 732 (360 incompletely and 372 conventionally milked) could be used for the survival analysis. On average 56 cow lactations were available per farm (range $=12$ to 148).

A total of $37 \%(136 / 372)$ of cows among the conventional milking group and 38\% (136/360) in the incomplete milking group were culled before 450 DIM. After observing the plot of the log cumulative hazard against the $\log$ time, 3 cut points were identified as possible moments for change in culling hazard ratio between treatment groups: 21, 28, and 35 DIM. None of the 2-way interaction terms between time (dichotomous variable, with 0 and 1 representing culling DIM lower and higher than the cut point, respectively) and treatment were statistically significant. Furthermore, the 2-way interaction term between time natural logarithm and treatment was not statistically significant. Therefore, we concluded that the effect of treatment on culling hazard did not vary as function of time (i.e., the proportional hazards assumption was respected). Culling hazard in incompletely milked cows was $1.0(95 \%$ $\mathrm{CI}=0.82,1.3)$ times that of conventionally milked cows $(P=0.74)$. The effect of treatment on culling hazard did not vary across parity $(P=0.31)$. Kaplan-Meier survival curves are presented in Figure 1.

\section{Milk Weight}

From the 821 cow lactations enrolled in the project, observations from 7 cow lactations (1\%; 1 conventionally and 6 incompletely milked) could not be matched 


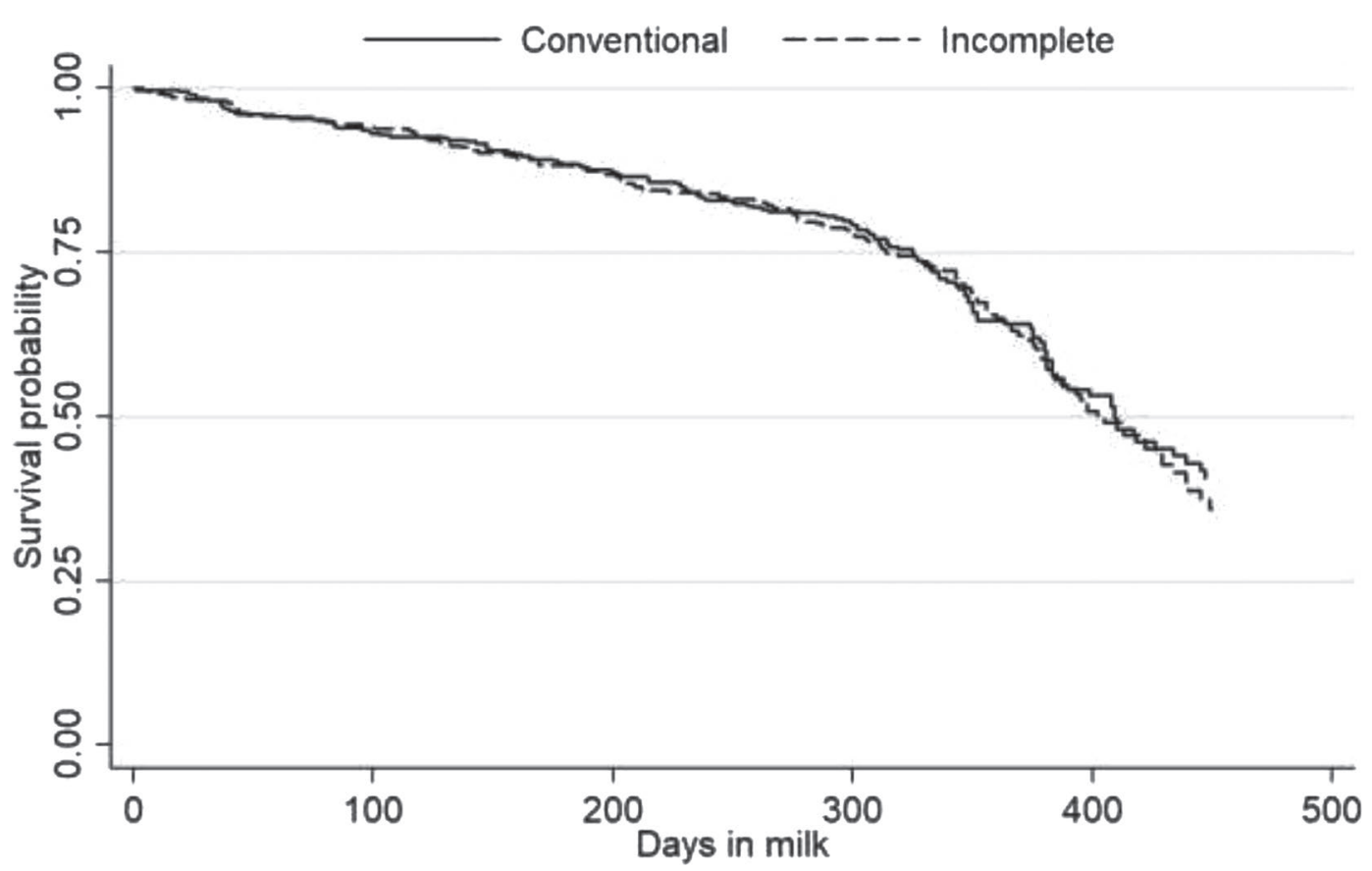

Figure 1. Kaplan-Meier survival curves illustrating survival probability for 732 multiparous cow lactations from 13 commercial herds enrolled in a randomized controlled trial (dash line represents cows incompletely milked; full line represents cows conventionally milked).

to any production record and were, therefore, missing. The data structure of the data set used for the milk weight analyses is presented in Table 1. For analysis, 814 cow lactations were available; on average, 119 observations were available per cow lactation (range $=2$ to 305$)$.

The linear mixed model with milk weight as outcome showed some level of heteroscedasticity; therefore, several transformations of the milk weight variable were evaluated to improve homoscedasticity. The squared root transformation $(\sqrt{ }$ milk weight) led to a certain improvement of the normality and homoscedasticity assumptions, but some degree of heteroscedasticity could still be observed. The results presented below should, therefore, be interpreted with caution.
Figure 2 illustrates distribution of milk weight least squares means (in $\sqrt{\mathrm{kg}} / \mathrm{d}$ ), after applying the square root transformation, for conventionally and incompletely milked cows between WIM 2 and 44. The effect of the treatment on square-rooted milk weight varied as function of WIM $(P=0.02$; Figure 2). However, after adjusting for multiple comparisons, we found no significant differences between treatment groups for any of the WIM. During WIM 2 to 9,10 to 17,18 to 25, 26 to 33 , and 34 to 44 , the conventionally milked cows produced, on average, 40.9, 39.6, 34.8, 29.8, and $23.4 \mathrm{~kg} / \mathrm{d}$, respectively. During the same time periods, incompletely milked cows produced, on average, 39.9, $39.1,34.2,29.1$, and $22.4 \mathrm{~kg} / \mathrm{d}$, respectively. The effect of treatment on square-rooted milk weight was

Table 1. Structure of the data set used for investigating the effect of incomplete milking during the early lactation on milk weight ${ }^{1}$

\begin{tabular}{lccc}
\hline & & \multicolumn{2}{c}{ Replication at level above ${ }^{2}$} \\
\cline { 3 - 4 } Level & No. of units & Mean & Range \\
\hline Farm & 13 & - & - \\
Cow lactations & 814 & 62.6 & $12-159$ \\
Daily milk yield observations & 97,487 & 119.7 & $2-305$ \\
\hline${ }^{1}$ Data obtained from a randomized controlled trial conducted on 846 cow lactations from 13 commercial dairies. \\
${ }^{2}$ Number of observations per cluster. For instance, number of daily milk yield observations per cow, or number \\
of cow lactations per farm.
\end{tabular}




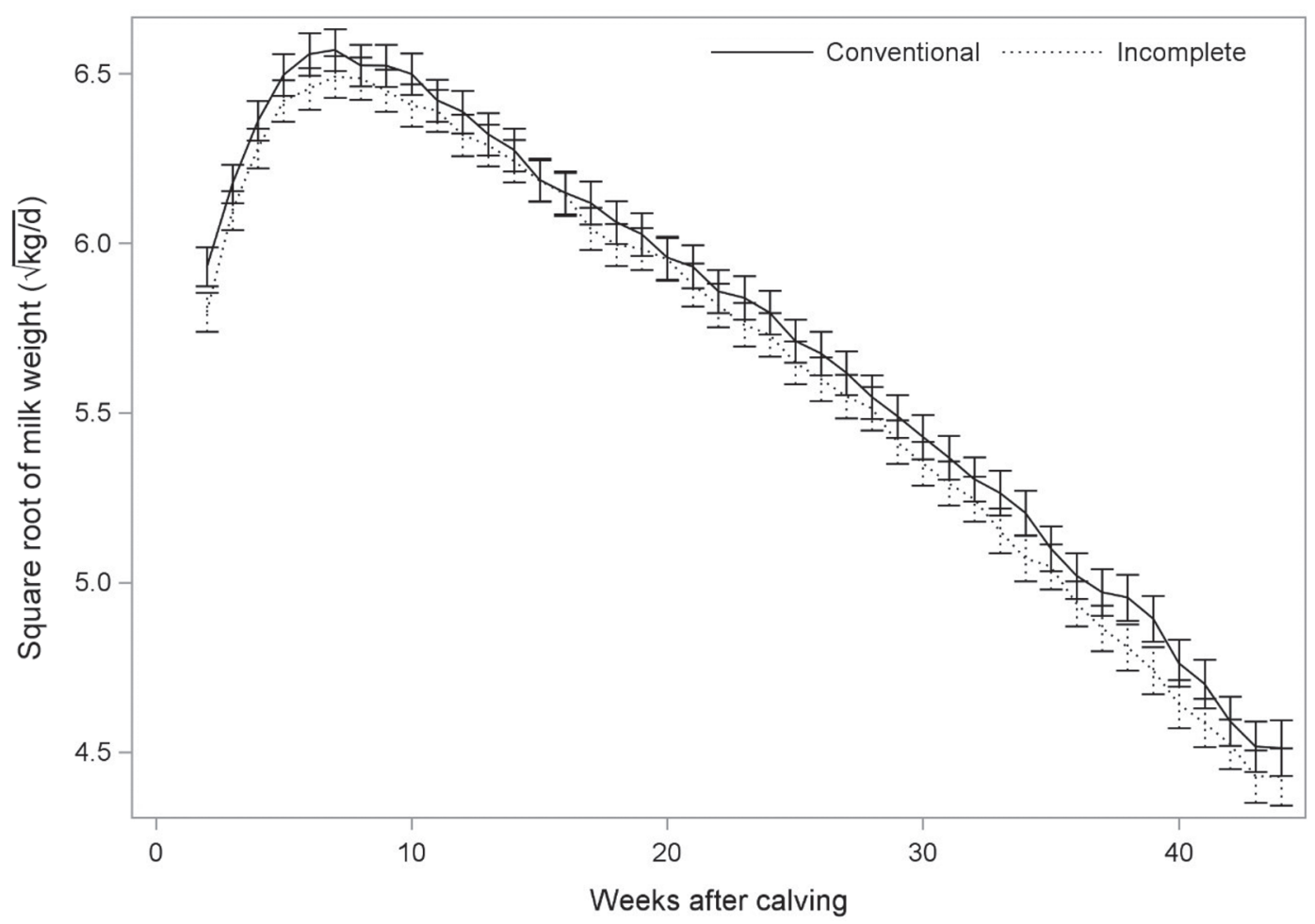

Figure 2. Square root of milk weight LSM (in kg/d) in conventionally milked cows (full line) and cows incompletely milked during the first 5 DIM (dash line). The LSM estimates were obtained using a linear mixed model using data from a randomized controlled trial conducted on 814 dairy cow lactations from 13 commercial herds; error bars represent unadjusted 95\% CI (i.e., not adjusted for multiple comparisons).

not modified by parity level $(P=0.91$ for the 3 -way interaction).

\section{Fat and Protein Concentrations}

For the same reasons pointed in the culling section, from the 821 cow lactations enrolled in the project, observations from 84 cow lactations $(10 \%$; 45 from the conventional milking group and 39 from the incomplete milking group) were missing. The structure of the data set used for fat and protein concentration analyses is presented in Table 2. From the 737 cow lactations that were included in the analysis, on average, 7 observations were available per cow lactation (range: 1 to 17 ).
Fat. The effect of the incomplete milking on milk fat concentration did not vary across WIM and it was not modified by parity level $(P=0.12$ for the triple interaction). Figure 3 illustrates distribution of milk fat least squares means (in \%) for conventionally and incompletely milked cows between WIM 2 and 44 . We found no statistically significant differences in fat concentration between conventionally and incompletely milked cows for any of the WIM studied.

Protein. The effect of the incomplete milking on milk protein concentration did not vary across WIM and it was not modified by parity level $(P=0.99$ for the triple interaction). Figure 4 illustrates distribution of milk protein least squares means (\%) for convention-

Table 2. Structure of the data set used for investigating the effect of incomplete milking during the early lactation on milk protein and fat concentrations ${ }^{1}$

\begin{tabular}{|c|c|c|c|}
\hline \multirow[b]{2}{*}{ Level } & \multirow[b]{2}{*}{ No. of units } & \multicolumn{2}{|c|}{ Replication at level above ${ }^{2}$} \\
\hline & & Mean & Range \\
\hline Farm & 13 & - & - \\
\hline Cow lactations & 737 & 56.7 & $12-155$ \\
\hline Daily milk composition observations & 5,825 & 7.9 & $1-17$ \\
\hline
\end{tabular}


ally and incompletely milked cows between WIM 2 and 44. As with fat concentration, we found no statistically significant differences in protein concentration between conventionally and incompletely milked cows for any of the WIM studied.

\section{$E C M$}

For the previously mentioned reasons, from the 821 cow lactations enrolled in the project, observations on milk composition of 134 cow lactations (17\%; 70 conventionally and 64 incompletely milked) were missing. The data structure of the data set used for the ECM analyses is presented in Table 3. From the 687 cow lactations that entered the analysis, on average, 79 daily ECM measures were available per cow lactation (range $=1$ to 264 ).

Figure 5 illustrates ECM least squares means (in $\mathrm{kg} / \mathrm{d}$ ), for conventionally and incompletely milked cows between WIM 2 and 44. The treatment-ECM relationship varied as function of WIM $(P<0.01$; Figure 5$)$. After adjusting for multiple comparisons, the only difference in ECM between groups was found during WIM 38 , in which incompletely milked cows had a predicted ECM $2.7 \mathrm{~kg} / \mathrm{d}$ inferior to that of conventionally milked cows $(95 \% \mathrm{CI}=-0.2,-5.2 \mathrm{~kg} / \mathrm{d})$. In the other periods, the ECM was comparable between treatment groups. The effect of treatment on ECM varied by parity level $(P<0.01$ for the 3 -way interaction term). However, after adjusting for multiple comparisons, we found no difference between treatment groups for none of the parity levels for each WIM.

\section{DISCUSSION}

Our study is the first to illustrate the effect of an incomplete milking protocol during the first 5 DIM on culling and milk production and composition throughout the whole lactation. Assuming that the treatment protocol was applied strictly following recommendations, the level of milk withdrawal in the incompletely milked group was about 48, 39, 42, and $47 \%$ of the conventional group on DIM 2, 3, 4, and 5, respectively.

In general, our results suggest that the incomplete milking has no effect on milk production and composition, except for WIM 38, for which incompletely milked cows seem to have a lower ECM than conventionally milked cows. No obvious explanation exists for this finding, as we would expect a higher effect of treatment shortly after its application rather than at the end of

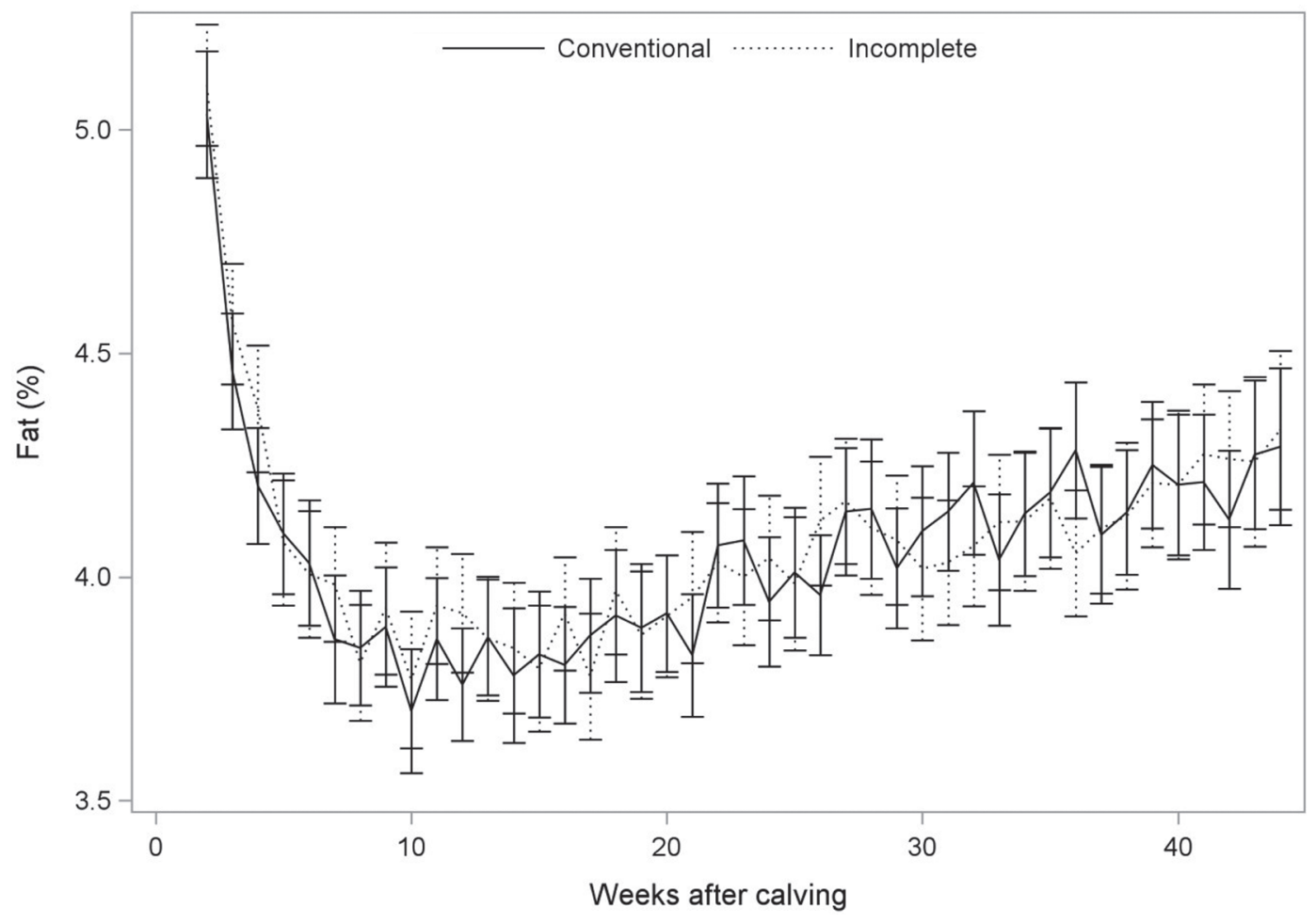

Figure 3. Milk fat concentration LSM (in \%) in conventionally milked cows (full line) and cows incompletely milked during the first 5 DIM (dash line). The LSM estimates were obtained using a linear mixed model using data from a randomized controlled trial conducted on 737 dairy cow lactations from 13 commercial herds; error bars represent unadjusted 95\% CI (i.e., not adjusted for multiple comparisons). 


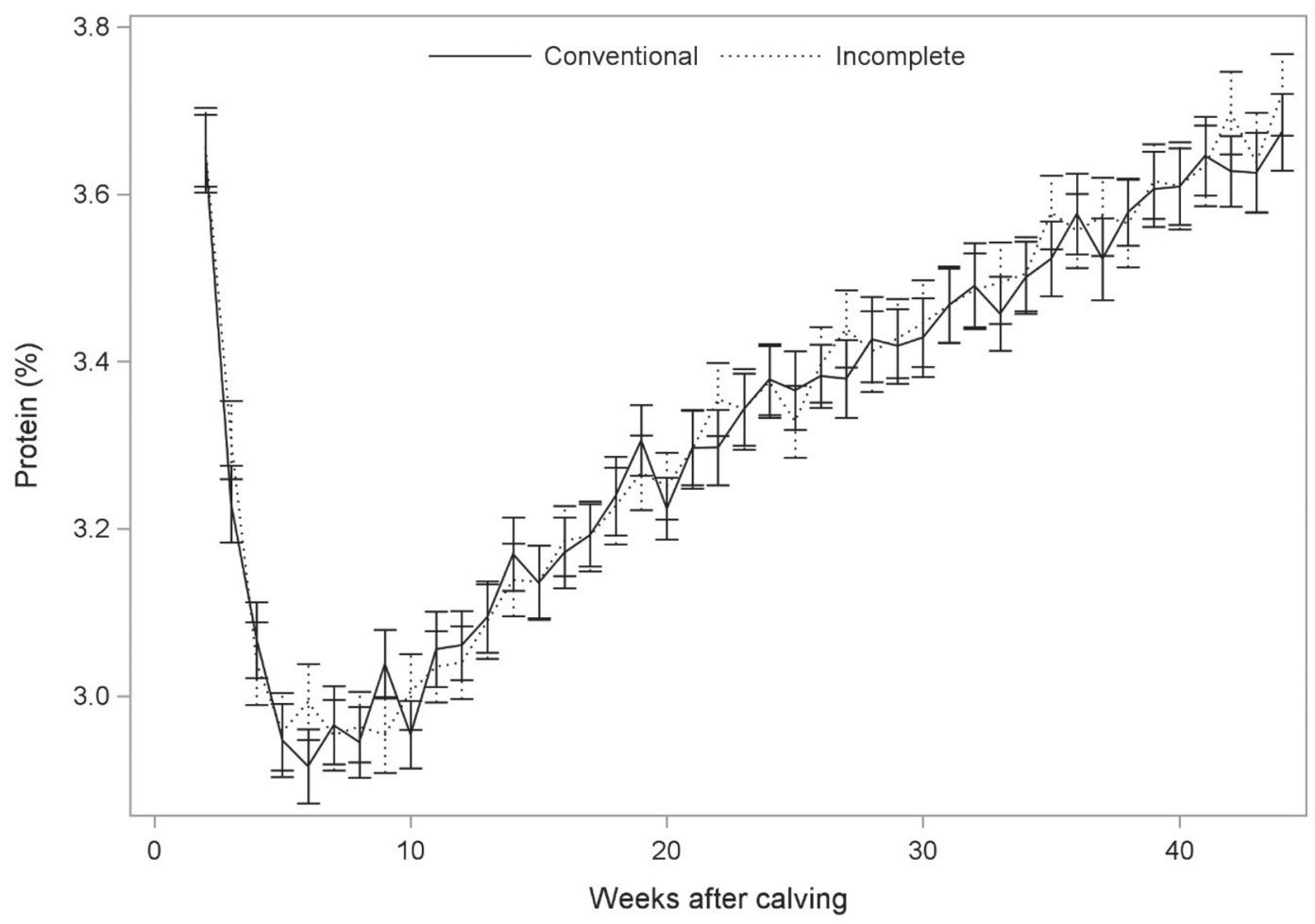

Figure 4. Milk protein concentration LSM (in \%) in conventionally milked cows (full line) and cows incompletely milked during the first 5 DIM (dash line). The LSM estimates were obtained using a linear mixed model using data from a randomized controlled trial conducted on 737 dairy cow lactations from 13 commercial herds; error bars represent unadjusted 95\% CI (i.e., not adjusted for multiple comparisons).

the lactation. However, in our study, ECM could only be calculated between the first and the last DHIA test, which resulted in a smaller number of ECM observations at the beginning and toward the end of the lactation (i.e., after the last DHIA test). As ECM records were scarce in the end of the lactation, some individual observations may have had a higher influence on the results, and so the difference found on WIM 38 could be caused by a few deviated observations. Differences in ECM observed toward the end of the lactation could be investigated in future research, for instance, using AMS herds collecting daily milk yield, fat, and protein milk concentrations.
To our knowledge, only one study evaluated the effect of an incomplete milking for a short period of time in the early lactation on dairy cattle milk production and composition (Carbonneau et al., 2012). In that study, the quantity of milk collected in cows in the incompletely milked group was about 43, 35, 34, 38, and $36 \%$ of the conventional group on DIM 1, 2, 3, 4, and 5, respectively. Those authors only observed milk production levels between 1 and 9 WIM and concluded that milk weight of cows incompletely milked rapidly reached similar levels to that of control cows soon after the end of treatment. Regarding milk protein and fat concentrations, Carbonneau et al. (2012) only found

Table 3. Structure of the data set used for investigating the effect of incomplete milking during the early lactation on $\mathrm{ECM}^{1}$

\begin{tabular}{lccc}
\hline & & \multicolumn{2}{c}{ Replication at level above $^{2}$} \\
\cline { 3 - 4 } Level & No. of units & Mean & Range \\
\hline Farm & 13 & $-\overline{5}$ & -155 \\
Cow lactations & 687 & 78.9 & $1-264$ \\
Daily milk yield observations & 54,326 & \\
\hline
\end{tabular}

${ }^{1}$ Data obtained from a randomized controlled trial conducted on 846 cow lactations from 13 commercial dairies.

${ }^{2}$ Number of observations per cluster. For instance, number of daily milk yield observations per cow, or number of cow lactations per farm. 
differences during WIM 2, in which fat concentration was lower and protein concentration was higher in the milk of incompletely milked cows compared with the control group, but no differences were found in the remaining of the study period.

Other studies were conducted using a half-udder design to understand the effect of an incomplete milking on milk production. Wilde et al. (1989) showed that an incomplete milking in dairy goats (defined as a gland with around $100 \mathrm{~mL}$ left behind at the end of milking) affects local enzyme activity with a reduction of total protein synthesis and partial secretory cellular involution if it lasts $24 \mathrm{wk}$, but not if it lasts only $2 \mathrm{wk}$. Although ran in a different species and with a different study design, the results observed by Wilde et al. (1989) also support the findings of the current study, where a relatively short period of incomplete milking was used. A more recent study from Penry et al. (2017), conducted in dairy cows, showed that an incompletely milked half-udder (defined as approximately $30 \%$ of total milk yield left behind at the end of milking) had lower milk production rate $(0.73 \mathrm{~kg} / \mathrm{h})$ than a completely milked half-udder $(0.97 \mathrm{~kg} / \mathrm{h})$, without an effect on milk composition. In that study, however, the treatment was applied for a longer period (from 5 to 47 DIM) compared with our study (1-5 DIM). Moreover, due to the half-udder design used by Penry et al. (2017), we could hypothesize the levels of galactopoietic hormones to be the same for both treated and control quarters; thus, the response observed in treated quarters in their study was possibly solely due to local quarter-level response (rather than local and central changes). In our study, the treatment could have induced both local and central responses, but minimal differences in milk yield were observed between groups. Thus, a discrepancy seems to exist between Penry et al. (2017) and the current study, and this divergence might have been caused by the very short treatment duration used in our study.

Considerable research has been produced on automatic teat cup removers and their effect on residual milk and subsequent milk production. In general, milking is considered optimal if it is conducted as gently, quickly, and completely (no residual milking) as possible (Reinemann, 2012), and without a negative effect on health and productivity (Lollivier et al., 2002). However, Hultén (2016) showed that take-off levels (i.e., milk flow rate threshold that leads to the detachment of the teat cups) of 100 or of $500 \mathrm{~g} / \mathrm{min}$ led to similar amounts of residual milking (approximately 1 $\mathrm{kg}$ /quarter), and that this level of residual milk did

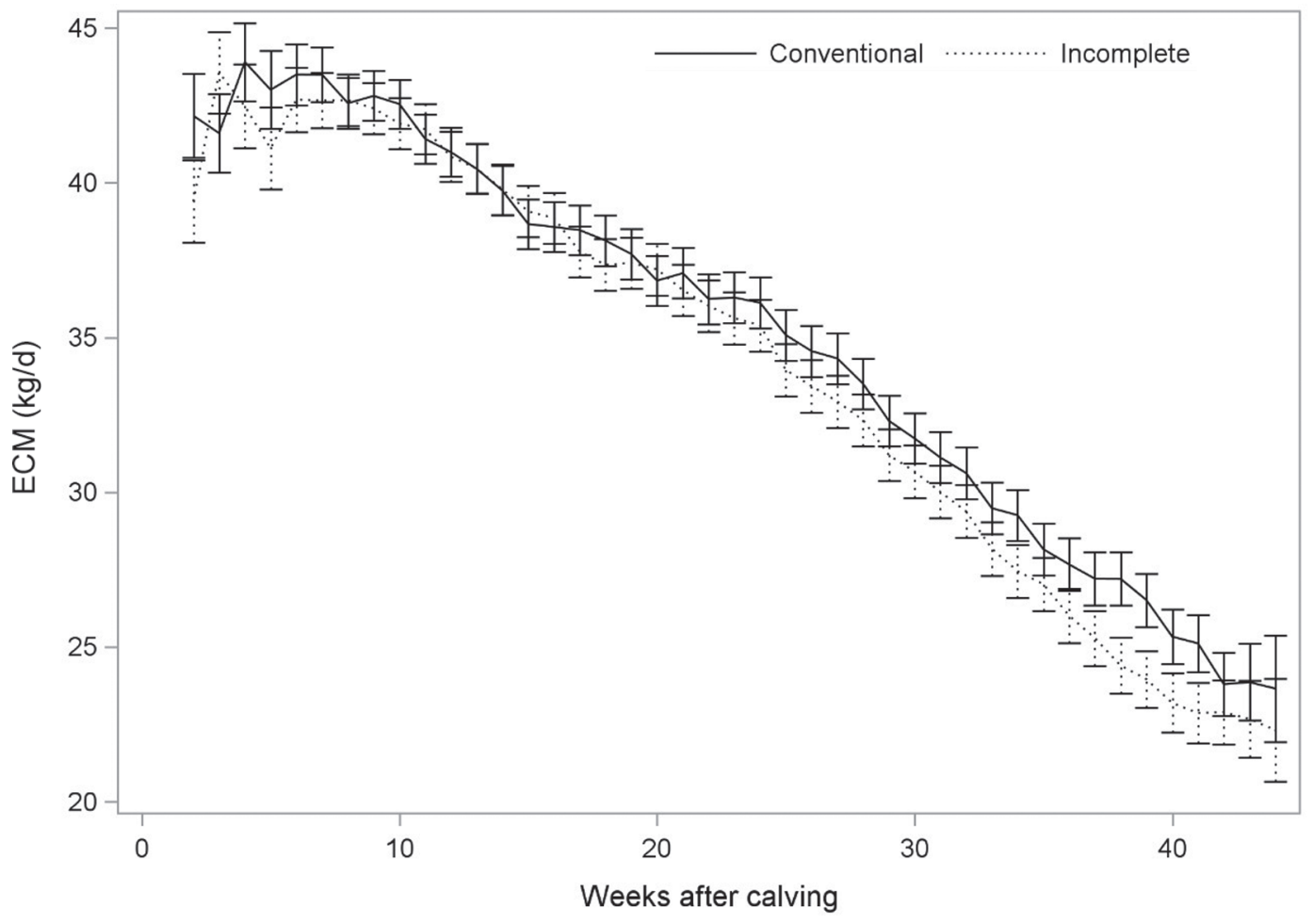

Figure 5. Energy-corrected milk LSM (in kg/d) in conventionally milked cows (full line) and cows incompletely milked during the first 5 DIM (dash line). The LSM estimates were obtained using a linear mixed model using data from a randomized controlled trial conducted on 687 dairy cow lactations from 13 commercial herds; error bars represent unadjusted $95 \%$ CI (i.e., not adjusted for multiple comparisons). 
not affect daily milk yield or composition. Jago et al. (2010) and Clarke et al. (2004) also compared similar cutoff levels and did not find any negative consequences on milk production, even with higher residual milking levels varying from 2 to $7 \mathrm{~kg}$ /quarter in Clarke et al. (2004). Although these studies were conducted under different scenarios (i.e., different treatment durations or moments in lactation), none showed significant effects on milk yield. The literature on automatic teat cup removers supports, therefore, the absence of a negative effect of our very short duration incomplete milking protocol on milk production.

Moreover, Bach and Busto (2005) found that teat cup attachment failures in an AMS occurring at the beginning of the lactation had a lower effect on subsequent milk yield than if they occurred near the end of the lactation. Their conclusion was that milking failure affects milk emptying but not mammary cell number. These results might also explain, in part, the absence of a sustained effect of our incomplete milking protocol on overall milk production in the current study.

Finally, Roberts et al. (2012) found that odds of culling within the first 60 DIM were increased by 1.8 in cows presenting hyperketonemia (BHB blood concentration $\geq 1.2 \mathrm{mmol} / \mathrm{L}$ ) during the first WIM. As the incomplete milking was found to reduce odds of hyperketonemia (Carbonneau et al., 2012; Morin et al., 2018), we would have expected to observe a preventive effect of the incomplete milking on culling; however, this was not the case in our study. Many internal (e.g., parity, health status) and external (e.g., need for producing more milk, milk/price) factors will affect the producer's decision whether to cull a cow (Bell et al., 2010). The herds followed in this RCT were shown to have a relatively low prevalence of hyperketonemia in the early lactation ( $10.7 \%$ between 4 and 7 DIM and $19.4 \%$ between 8 and 17 DIM; Morin et al., 2018) compared with research conducted on 4,242 DHIA herds in the same Canadian region (25.8 and $34.6 \%$ during WIM 2 for parity 2 and 3 cows, respectively; Santschi et al., 2016). Culling reasons in the herds followed in the current study were, therefore, possibly less influenced by hyperketonemia and, instead, driven by other internal or external factors.

\section{CONCLUSIONS}

In the current study, an incomplete milking during the first 5 DIM did not lead to significant differences in culling hazard, milk weight, and milk fat and protein concentrations when compared with conventional milking. However, a lower ECM yield was observed for WIM 38 in incompletely milked cows. The incomplete milking during the first 5 DIM is an interesting strategy for controlling the NEB with relatively small negative effects on cow productivity.

\section{ACKNOWLEDGMENTS}

The authors acknowledge the financial support from Novalait (Québec, Canada), Fonds de recherche du Québec-Nature et technologies (Québec, Canada), and by the Natural Sciences and Engineering Research Council of Canada (Ottawa, ON, Canada) Discovery Grant program of one of the authors (S. D.). The first author (C. K.) was supported by a Natural Sciences and Engineering Research Council of Canada-Collaborative Research and Training Experience in milk quality scholarship. The authors also gratefully acknowledge the participating farmers, as well as Roxanne Mandeville and Jean-Philippe Pelletier (Centre hospitalier universitaire vétérinaire, St-Hyacinthe, QC, Canada) for their technical support.

\section{REFERENCES}

Bach, A., and I. Busto. 2005. Effects on milk yield of milking interval regularity and teat cup attachment failures with robotic milking systems. J. Dairy Res. 72:101-106.

Bell, M. J., E. Wall, G. Russell, D. J. Roberts, and G. Simm. 2010. Risk factors for culling in Holstein-Friesian dairy cows. Vet. Rec. 167:238-240.

Busato, A., D. Faissle, U. Kupfer, and J. W. Blum. 2002. Body condition scores in dairy cows: Associations with metabolic and endocrine changes in healthy dairy cows. J. Vet. Med. A Physiol. Pathol. Clin. Med. 49:455-460.

Carbonneau, E., A. M. de Passillé, J. Rushen, B. G. Talbot, and P. Lacasse. 2012. The effect of incomplete milking or nursing on milk production, blood metabolites, and immune functions of dairy cows. J. Dairy Sci. 95:6503-6512.

Clarke, T., E. M. Cuthbertson, R. K. Greenall, M. C. Hannah, E. Jongman, and D. Shoesmith. 2004. Milking regimes to shorten milking duration. J. Dairy Res. 71:419-426.

Dohoo, I. R., S. W. Martin, and H. Stryhn. 2009. Veterinary Epidemiologic Research. 2nd ed. AVC-Inc., Charlottetown, Canada.

Duffield, T. F., K. Lissemore, B. McBride, and K. Leslie. 2009. Impact of hyperketonemia in early lactation dairy cows on health and production. J. Dairy Sci. 92:571-580.

Grummer, R. R., D. G. Mashek, and A. Hayirli. 2004. Dry matter intake and energy balance in the transition period. Vet. Clin. North Am. Food Anim. Pract. 20:447-470.

Hultén, C. 2016. The effect of different cluster take-off levels at udder quarter in combination with feeding during milking on milk production in dairy cows-Milk yield, milk composition and milking time. MS Thesis, Department of Animal Nutrition and Management, Swedish Univ. of Agricultural Sciences, Uppsala, Sweden.

Jago, J. G., J. K. Burke, and J. H. Williamson. 2010. Effect of automatic cluster remover settings on production, udder health, and milking duration. J. Dairy Sci. 93:2541-2549.

Krug, C., T. J. DeVries, J.-P. Roy, J. Dubuc, and S. Dufour. 2017. Incomplete milking in early lactation does not affect dairy cows resting behaviors: Results from a randomized controlled trial. Front. Vet. Sci. 4:66.

Lacasse, P., V. Lollivier, R. Bruckmaier, Y. Boisclair, G. Wagner, and M. Boutinaud. 2011. Effect of the prolactin-release inhibitor quinagolide on lactating dairy cows. J. Dairy Sci. 94:1302-1309.

Loiselle, M. C., C. Ster, B. G. Talbot, X. Zhao, G. F. Wagner, Y. R. Boisclair, and P. Lacasse. 2009. Impact of postpartum milking 
frequency on the immune system and the blood metabolite concentration of dairy cows. J. Dairy Sci. 92:1900-1912.

Lollivier, V., J. Guinard-Flament, M. Ollivier-Bousquet, and P. Marnet. 2002. Oxytocin and milk removal: Two important sources of variation in milk production and milk quality during and between milkings. Reprod. Nutr. Dev. 42:173-186.

Morin, P.-A., C. Krug, Y. Chorfi, J. Dubuc, P. Lacasse, J.-P. Roy, D. Santschi, and S. Dufour. 2018. A randomized controlled trial on the effect of incomplete milking during early lactation on ketonemia and body condition loss in Holstein dairy cows. J. Dairy Sci. 101:4513-4526.

NRC. 2001. Nutrient Requirements of Dairy Cattle. 7th ed. Natl. Acad. Press, Washington, DC.

O’Driscoll, K., G. Olmos, S. Llamas Moya, J. F. Mee, B. Earley, D. Gleeson, B. O'Brien, and L. Boyle. 2012. A reduction in milking frequency and feed allowance improves dairy cow immune status. J. Dairy Sci. 95:1177-1187.

Penry, J. F., E. Endres, B. de Bruijn, A. Kleinhans, P. Crump, D. Reinemann, and L. Hernandez. 2017. Effect of incomplete milking on milk production rate and composition with 2 daily milkings. J. Dairy Sci. 100:1535-1540.

Reinemann, D. J. 2012. The smart position on teat condition. Pages 124-131 in Proc. New Zealand Milk Quality Conference, Hamilton, New Zealand. New Zealand Veterinary Association, Hamilton, New Zealand.
Roberts, T., N. Chapinal, S. J. LeBlanc, D. F. Kelton, J. Dubuc, and T. F. Duffeld. 2012. Metabolic parameters in transition cows as indicators for early-lactation culling risk. J. Dairy Sci. 95:3057-3063.

Santschi, D. E., R. Lacroix, J. Durocher, M. Duplessis, R. K. Moore, and D. M. Lefebvre. 2016. Prevalence of elevated milk beta-hydroxybutyrate concentrations in Holstein cows measured by Fourier-transform infrared analysis in Dairy Herd Improvement milk samples and association with milk yield and components. J. Dairy Sci. 99:9263-9270.

Ster, C., M.-C. Loiselle, and P. Lacasse. 2012. Effect of postcalving serum nonesterified fatty acids concentration on the functionality of bovine immune cells. J. Dairy Sci. 95:708-717.

Suriyasathaporn, W., C. Heuer, E. N. Noordhuizen-Stassen, and Y. H. Schukken. 2000. Hyperketonemia and the impairment of udder defense: a review. Vet. Res. 31:397-412.

van Knegsel, A. T., G. de Vries Reilingh, S. Meulenberg, H. van den Brand, J. Dijkstra, B. Kemp, and H. K. Parmentier. 2007. Natural antibodies related to energy balance in early lactation dairy cows. J. Dairy Sci. 90:5490-5498.

Wilde, C. J., D. R. Blatchford, C. H. Knight, and M. Peaker. 1989 Metabolic adaptations in goat mammary tissue during long-term incomplete milking. J. Dairy Res. 56:7-15. 